\title{
CALLUS FORMATION IN ANTHER CULTURE OF TEA CLONES, CAMELLIA SINENSIS (L.) O.Kuntze
}

\author{
THAYAMINI H.SERAN ${ }^{*}$, KSHANIKA HIRIMBUREGAMA ${ }^{2}$, W.K.HIRIMBUREGAMA ${ }^{2}$ \\ and V.SHANMUGARAJAH" \\ 'Department of Agronomy, Eastern University, Chenkalady. \\ Department of Botany, University of Colombo, Colombo 3. \\ 'Division of Plant Breeding and Propagation, Tea Research Institute, Talawakelle.
}

(Received: 14 September 1998 ; accepted: 02 July 1999)

\begin{abstract}
This study was carried out to regenerate haploids from cultured anthers of tea clones. Morphological and histological studies on the anther callus development revealed that nuclei of numerous microspores began to divide unequally, forming multicellular structures during the first week of culture and anther lohes swelled gradually until bursting. The rate of callus induction was rapid during 6-10 weeks and compact greenish calli were formed from anthers. Calli hecame more heterogeneous with time in culture. The determination of ploidy levels in anther callus showed that two levels of ploidy were present in callus. In the callus, the percentage of haploid cells was more $(68 \%)$ than that of diploid (6\%).
\end{abstract}

The study on comparison of callus growth in anthers of different clones indicated that the survival of anthers of three clones TRI 2043, TRI 2023 and TRI 2025 was high (highest was $98 \%$, the lowest $78 \%$ ) and calli were produced in anthers of all clones used in this trial. TRI 2043 exhibited relatively more callus formation $(76.2 \mathrm{mg}$ ) from anther cultured in half Murashige and Skoog (MS) medium with 2,4 D and BAP grown in light, followed by TRI 2023, TRI 2024, TRI 2025 and TRI 777. In the dark, significant callus growth was observed in four clones (TRI 2025, TRI 2024, TRI 2023 and TRI 777). Calli that formed in light turned dark green, meristemoid like structures after transfer to the same medium without 2,4 D. However; plantlets could not be regenerated.

Key Words: Anther culture, callus, haploid production, microspores, tea clones.

\section{INTRODUCTION}

Tea, Camellia sinensis (L.) is cultivated commercially for its tender leaf which is used as a beverage. In Sri Lanka, it is grown under various types of soil and climatic conditions with different pests and disease problems. Therefore, it is necessary to provide good planting material to growers in order to ensure highest possible yield of tea with high quality. As the demand for genetically uniform and agronomically superior planting material is increasing the creation of new and commercially desirable tea cultivars become essential and this can be achieved only by a proper programme of breeding. For commercial planting,

\footnotetext{
* Corresponding author
} 
high yielding clones with good leaf quality have been obtained from hybridization. However, self incompatibility, low seed setting ability of high yielding clones ${ }^{1}$, rapid loss of viability of seeds and long durations of each sexual cycle have been barriers in the tea breeding programme.

Anther culture technique can play an important role in genetics and plant breeding programme of tea. Even though anther culture technique has been widely used in crop improvement in non-woody plants not much work has been done in woody plants. Anther culture in tea was first described in $1969^{2}$. But very few attempts have been made on anther culture of tea. Differentiation of anther callus into a radicated structure in which vascular bundles were found was reported in $1970^{3}$. Further work on the differentiation rate of the root derived from tea anther cultures was described in $1981^{4}$. Therefore, an attempt was made to produce haploids from cultured anthers of Sri Lankan tea clones.

\section{METHODS AND MATERIALS}

Plant material : Unopened floral buds (anthers containing microspores at mid uninucleate stage) of clones TRI 2025, TRI 2023, TRI 2024, TRI 2043 and TRI 777 were harvested separately in petri dishes from the seed garden in St.Coombs estate, Talawakelle and stored in a refrigerator at 5 " $\mathrm{C}$ for 3 days. They were then sterilised with $70 \%$ ethanol for $1 \mathrm{~min}$ and $5 \%$ Clorox (sodium hypochlorite $5.25 \%$ ) for $10 \mathrm{~min}$. Then they were rinsed three times in sterile water and the anthers were excised from each bud.

Histological and morphological studies : In this experiment, excised 20 anthers of clone TRI 2025 were placed in each petri dish containing half MS medium (Murashige and Skoog $\left.{ }^{5}\right)$ supplemented with $2,4 \mathrm{D}(2.0 \mathrm{mg} / \mathrm{L})$ and BAP $(1.0 \mathrm{mg} / \mathrm{L})$ with 10 replicates. They were then incubated in white fluorescence light $(16 \mathrm{~h}, 2000$ lux). For cytological examination anthers were taken daily upto 7 days of inoculation and then weekly. They were examined as in wheat anther culture ${ }^{6}$.The weight of anther was recorded every week upto the first month of culture initiation. At monthly intervals, calli were transferred to the same medium but without $2,4 \mathrm{D}$ and kept in white fluorescence light (16 h, 2000 lux). Subculturing was done once a month. Colour and type of calli were observed and callus at $3^{\text {rd }}$ month was used to determine the ploidy levels.

Analysis of ploidy levels in callus : This experiment was done to confirm the haploid status of callus. Seventy five grams of callus was taken in a sterile petri dish and $1 \mathrm{ml}$ of high resolution DNA kit solution (commercial PARTEC buffer) was added to isolate the nuclei from cells. The sample was chopped gently with a razor blade in the petri dish containing the solution and the suspension was filtered through $50 \mu \mathrm{m}$ nylon mesh into a small tube to separate nuclei from the debris. Up to $2 \mathrm{ml}$ of DNA staining solution (commercial PARTEC solution) was then added. 
The samples were maintained at $0{ }^{\circ} \mathrm{C}$ following isolation of nuclei in order to decrease nuclease activity ${ }^{7}$. After the time required for staining, DNA of the sample was analysed in a Flow Cytometer (PARTEC, Munster, Germany). Integrals of each individual peak in the histogram were obtained using built in software ${ }^{8}$.

Callus formation : This experiment was done to study the response of anthers of different clones on callus formation. Ten excised anthers (microspores at mid uninucleate stage) of five clones viz: TRI 2025, TRI 2023, TRI 2024, TRI 2043 and TRI 777 were placed on half MS medium supplemented with 2,4 D (2.0 $\mathrm{mg} / \mathrm{L})$ in combination with $\operatorname{BAP}(1.0 \mathrm{mg} / \mathrm{L})$ or Kinetin $(1.0 \mathrm{mg} / \mathrm{L})$ or Kinetin $(1.0$ $\mathrm{mg} / \mathrm{L})$ and IAA (1.0 mg/L) as indicated in Table 1.

Table 1: Media used for induction of callus from anthers.

\begin{tabular}{ccc}
\hline Medium & Composition & $\begin{array}{c}\text { Culture } \\
\text { condition }\end{array}$ \\
\hline 1 & Half MS + 2, 4 D $(2.0 \mathrm{mg} / \mathrm{L})+\mathrm{BAP}(1.0 \mathrm{mg} / \mathrm{L})$ & light \\
2 & Half $\mathrm{MS}+2,4 \mathrm{D}(2.0 \mathrm{mg} / \mathrm{L})+\operatorname{Kinetin}(1.0 \mathrm{mg} / \mathrm{L})$ & dark \\
3 & Half $\mathrm{MS}+2,4 \mathrm{D}(2.0 \mathrm{mg} / \mathrm{L})+\operatorname{Kinetin}(1.0 \mathrm{mg} / \mathrm{L})+$ & \\
& IAA $(1.0 \mathrm{mg} / \mathrm{L})$ & $\operatorname{dark}$ \\
\hline
\end{tabular}

Each treatment was replicated 6 times. Bottles ( $4 \mathrm{~mm}$ diameter) containing medium 1 were kept in white fluorescence light $(16 \mathrm{~h}, 2000 \mathrm{lux})$ and the other two media were incubated in the dark. Subculturing was done once a month. In each treatment, the number of anthers that produced callus and the weight of callus were recorded at the $3^{\text {rd }}$ month. The data on the weight of callus was analysed using analysis of variance. Means were compared using Duncan's multiple range test". At the $3^{\text {rd }}$ month calli were transferred to the same media but without 2, $4 \mathrm{D}$ and kept in white fluorescence light ( $16 \mathrm{~h}, 3000 \mathrm{lux})$ for the regeneration of shoots.

\section{RESULTS}

\section{Histological study}

Nuclei of numerous microspores began to divide unequally, forming multicellular structures during the first week of culture. Microspores of those in which the division was observed increased in their original volume. The weight of anther significantly increased during the first month of culture initiation (Figure 1). Anther lobes swelled gradually until bursting. Callus mass consisted of tracheid elements and parenchyma cells with large vacuoles. All the different steps of embryogenesis from bicellular to embryo stages were observed during the first 3-8 weeks of culture. Very few number of small embryos was noticed in callus formed from anther, but it was not visible to the naked eye. 


\section{Morphological study}

Anther lobes started swelling in the $1^{\text {st }}$ week and $68 \%$ of anthers swelled in the $1^{\text {st }}$ month. Then, they split longitudinally and burst. Bursting of explants started in the $3^{\text {rd }}$ week. The rate of callus induction was rapid during 6-10 weeks. The callus formation from anthers was not observed in the first month (Figure 2). Compact greenish calli formed from anthers. When the callus aged, the development of the callus was slow and it became more heterogeneous with time in culture. Plant regeneration did not occur in any of the callus tissues during the 5 months of culture.

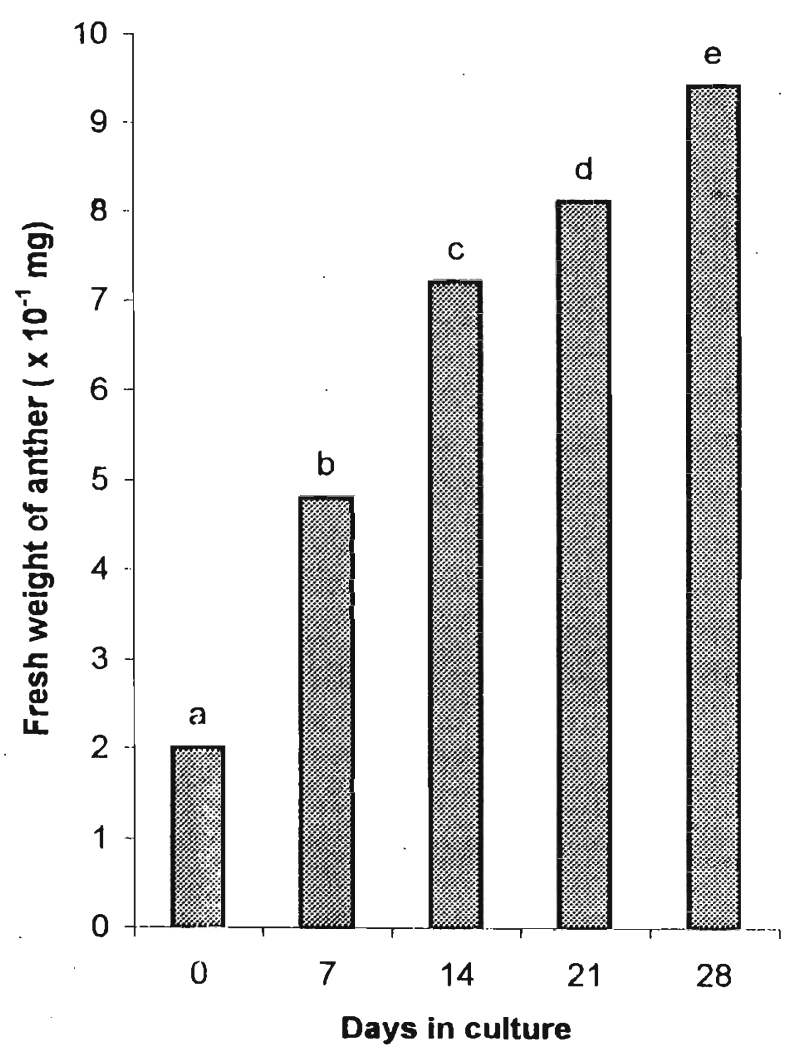

Figure 1: Growth of anther in half MS medium supplemented with 2,4D $(0.2 \mathrm{mg} / \mathrm{L})$ and BAP $(1.0 \mathrm{mg} / \mathrm{L})$.

Means with the same letters are not significantly different $(p=0.05)$ 


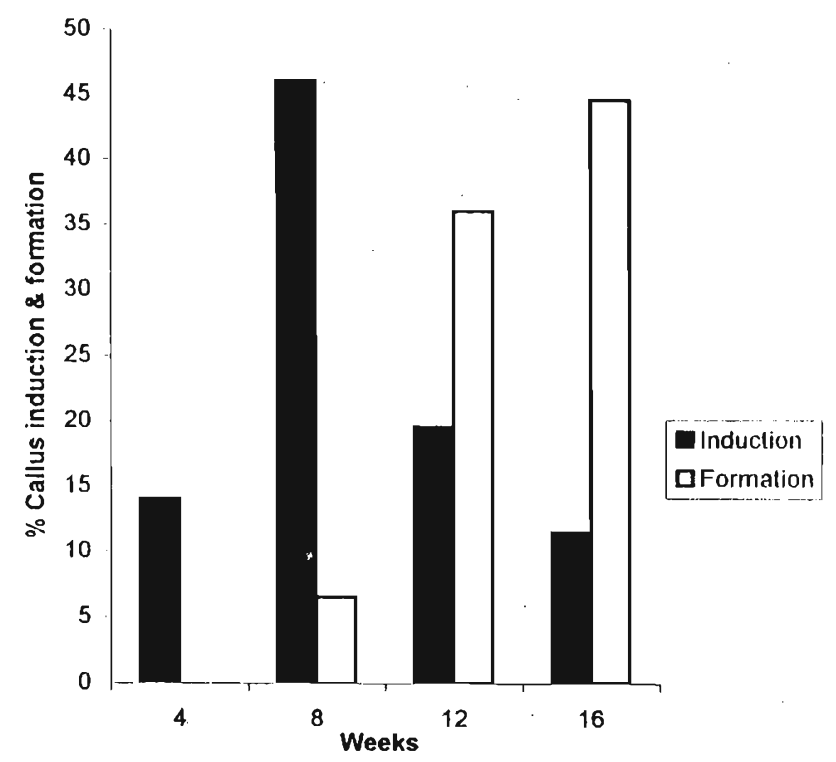

Figure 2: The rates of induction and formation of callus in anthers.

\section{Ploidy levels in callus}

In this study, first and second peaks were obtained at channel 80 and 160 respectively. The ratio of the mean channel numbers of peaks in the DNA histogram was calculated ${ }^{7}$. The value 1:2 obtained suggests that two levels of ploidy were present in the callus. When considering peak index and position at channel, first and second peaks should be haploid and diploid respectively. In the anther callus, haploid cells were more (68\%) than that of diploid (6\%). The resulting histogram with two peaks had coefficients of variation less than $8 \%$.

\section{Callus formation}

The survival of anthers of three clones TRI 2043, TRI 2023 and TRI 2025 was high (highest was $98 \%$, the lowest $78 \%$ ) in all media tested (Figure 3). After 6 weeks of incubation, compact greenish callus developed from anthers grown in light and whitish callus in the dark. Further, it was observed that calli were produced from anthers of all clones and the effect of different media on callus growth also varied. Callus induction was first observed in anthers of clone TRI 2023 and TRI 2043 cultured in light and also the frequency of their callus formation was about $50 \%$ (Figure 4 ). 
Of the five clones tested, TRI 2043 at the $3^{\text {rd }}$ month of incubation exhibited relatively more callus formation $(76.2 \mathrm{mg})$ from anther cultured in medium with 2,4 D and BAP grown in light, followed by TRI 2023 (43 mg) and TRI 2024 (30 $\mathrm{mg}$ ) as given in Figure 5. Significant callus formation was observed in anthers of four clones (TRI 2025, TRI 2024, TRI 2043 and TRI 777) when anthers were cultured in the medium with $2,4 \mathrm{D}$ and kinetin or in combination with IAA and grown in the dark.

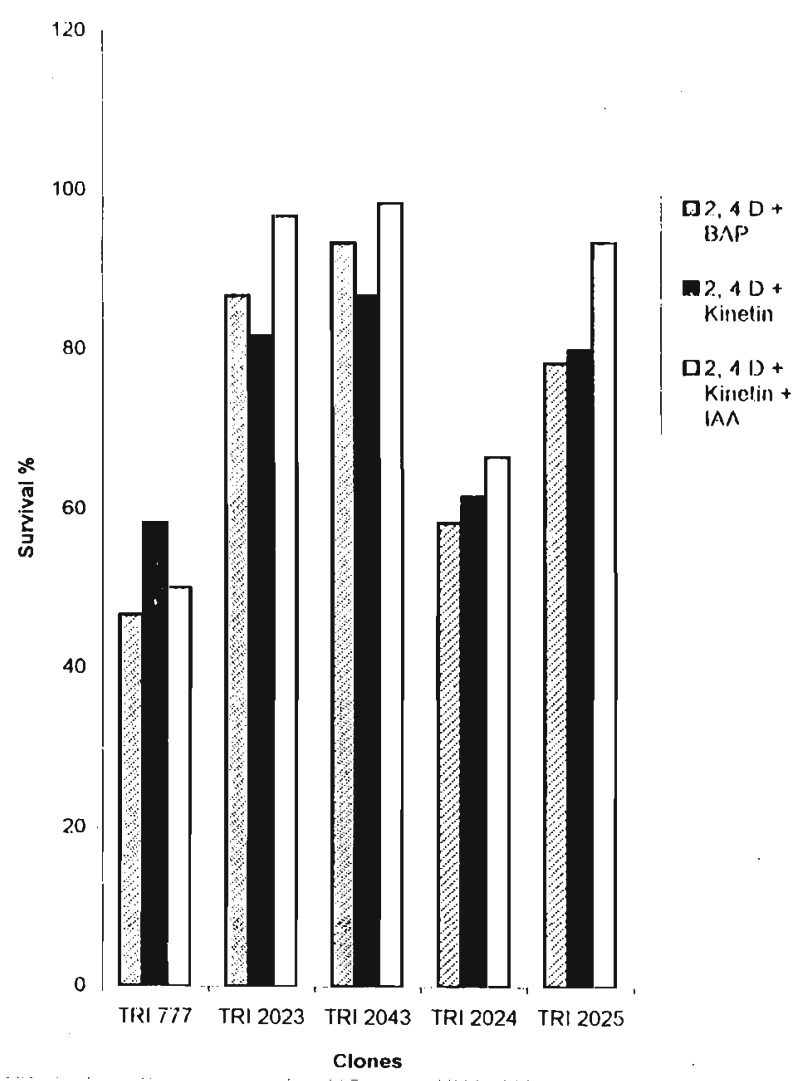

Figure 3 : Survival of anthers of tea clones in different culture media. 


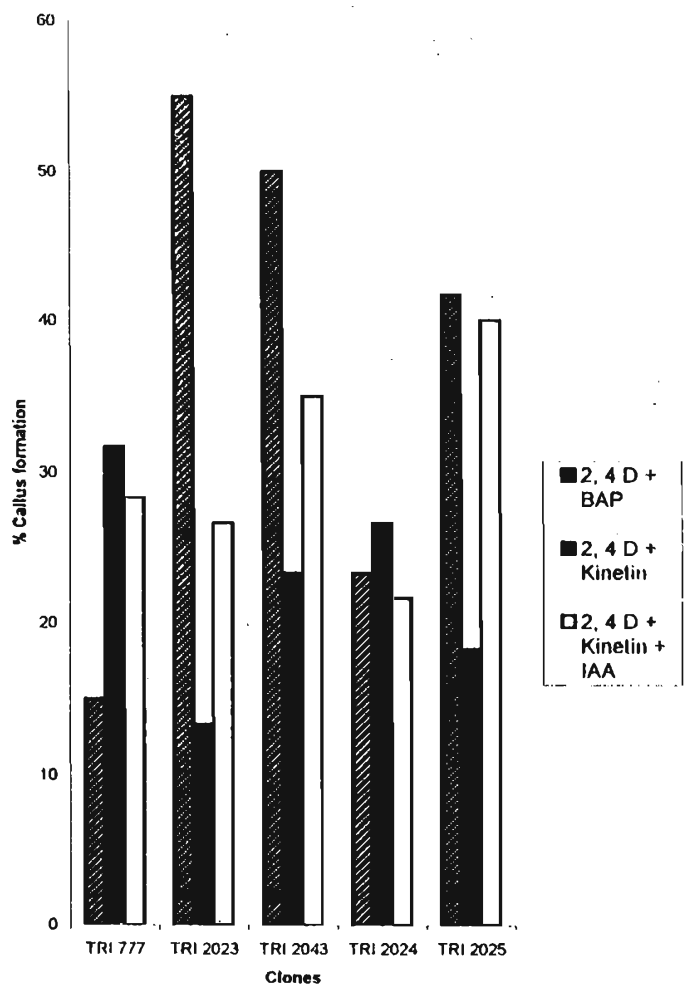

Figure 4: The percentage of callus formation in anthers of five clones.

\section{Regeneration of shoot bud from callus}

At the third month, calli developed from anthers of the five clones were transferred to the same medium devoid of 2,4 D and grown in light. Calli that grew in light turned dark green. Meristemoid like structures were observed after 5 weeks of transfer of calli to the same medium without $2,4 \mathrm{D}$. When calli formed in the dark were transferred to light condition, most of them turned brown and died. In some instances, they turned greenish yellow in colour after 2 months of transfer.

\section{DISCUSSION}

Microspores grow and develop into multicellular masses, embryos or pollen calli under favorable conditions ${ }^{10}$. The formation of these structures within the anther lobes could be the reason for the swelling of explants in culture. The two different processes that exist simultaneously are the formation of somatic calli and the initiation of microspore development into small embryos or pollen calli ${ }^{10}$. A 
first symmetric mitotic division gives rise to proembryos while asymmetric divisions originate callus ${ }^{11}$. Even though connective tissue of the anthers proliferated in priority during the first 2-3 weeks of culture this somatic callus then mostly degenerated while callus and embryos develop vigorously from microspores ${ }^{10}$. Sucrose is generally used at a concentration of $2-4 \%$ in anther culture $^{12}$. Effect of a high sucrose level in the induction medium is directly related to the regulation of osmotic pressure during growth induction and it prevents callus formation from somatic anther tissue $e^{1: 3}$. In responsive anthers, the wall tissues gradually turn brown and after 3-8 weeks burst open due to the pressure exerted by the growing pollen callus or pollen plant ${ }^{12}$.

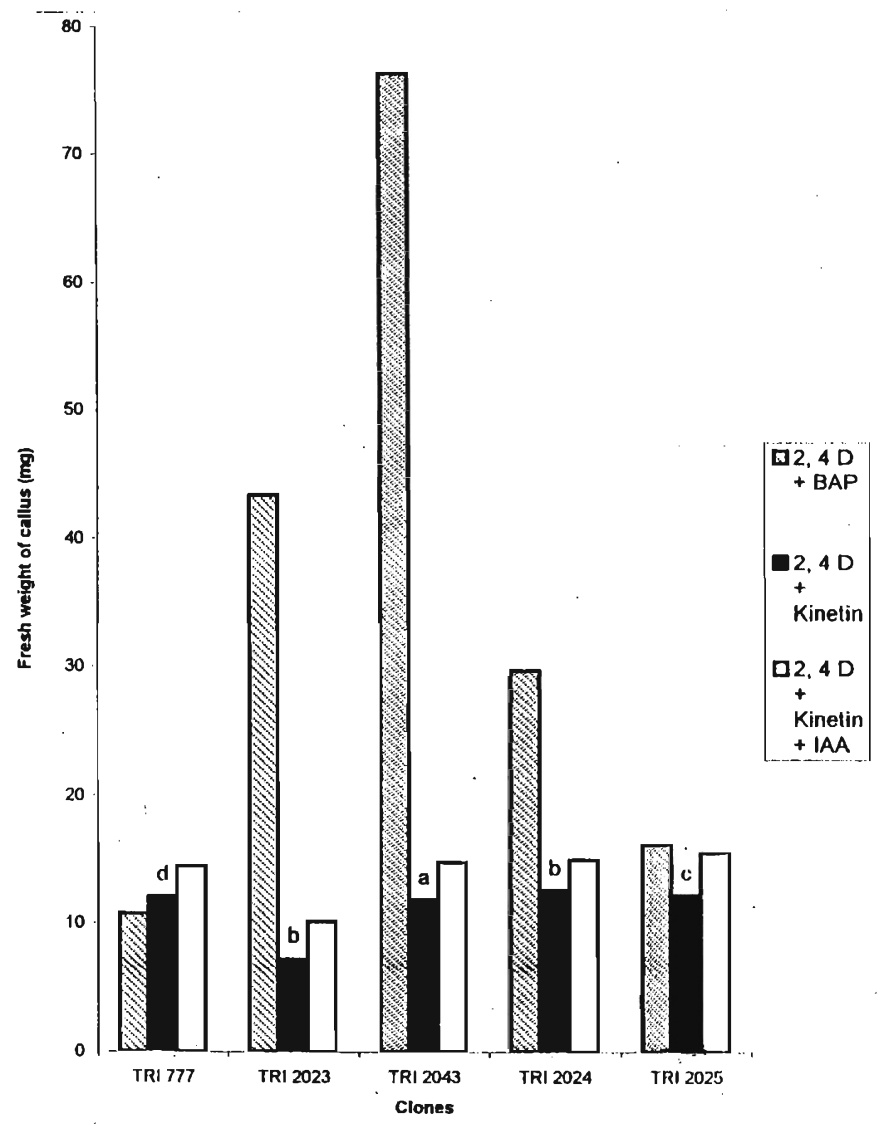

Figure 5: Comparison of callus growth in anthers of five clones after 3 months Means with the same letters are not significantly different $(p=0.05)$

The ploidy levels of the callus were determined by measuring the nuclear DNA content of the cells. The DNA content was measured automatically and rapidly using Ploidy Analyzer. All cells belonging to one peak have the same quality of measured cell substances (e.g. DNA). In the case of a DNA measurement of plant cells, a single peak represents one ploidy level and the peaks of higher ploidy levels 
appear on the right side of the histogram $\$$. As polyploid cells contain more than two chromosome sets, calculation of the $2 \mathrm{C}(\mathrm{C}=\mathrm{DNA}$ contents of haploid set of chromosomes) DNA content requires a knowledge of the ploidy level of the material ${ }^{7}$. In this experiment two levels of ploidy were present in the callus. With the knowledge of the material, these two levels of ploidy should be haploid and diploid. The resulting histogram with two peaks had coefficients of variation less than $8 \%$. Coefficient of variation ( $\mathrm{cv}=$ standard deviation divided by the mean) usually range from 1 to $10 \%$ ? Low cv values make it possible to estimate small. changes in nuclear DNA content. The higher $\mathrm{cv}$ values in the measurements of chopped plant tissues seem to be artefacts of mechanical destruction during chopping ${ }^{14}$. Its application is attractive for ploidy screening in a large number of plants ${ }^{15}$.

Compact greenish calli developed from anthers cultured in medium with 2,4 D and BAP grown in light and whitish calli in medium with 2,4 D and linetin or in combination with IAA grown in the dark. Auxin and cytokinin together are necessary for good callus formation ${ }^{16}$. Higher concentrations of non-phenoxy auxins (IAA, NAA or IBA) alone often promote root initiation rather than shoots whereas phenoxy-auxin $(2,4 \mathrm{D})$ promotes callus growth and embryogenesis ${ }^{17}$. Callus growth in anthers of each clone varied according to the culture media and conditions. This variation in callus growth may be due to the genotype of the donor plant. Similar findings were reported by others ${ }^{1 \$ 1 \%}$. According to these authors, when anthers of rice varieties are cultured in vitro they do not respond equally in producing callus and in regenerating plants. This could be due to genetic or environmental characteristics of different rice varieties. Calli that grew in light turned dark green after transfer of calli to the same medium without 2, $4 \mathrm{D}$. But plant regeneration did not occur in any of callus tissues during the five months of incubation. The use of $2,4 \mathrm{D}$ in combination with BAP proved to be better than that of IAA in combination with either kinetin or zeatin for the callus formation from sour cherry anthers ${ }^{21}$. Regeneration of shoots was observed four months after transfer of callus tissues to the same medium without $2,4 \mathrm{D}$.

Anther lobes swelled gradually due to the formation of multicellular structures. Then they burst and produced the calli and embryos. Two levels of ploidy (haploid and diploid) were present in the anther callus. The percentage of haploid cells in the callus was more $(68 \%)$ than that of diploid $(6 \%)$. Therefore, it would be possible to regenerate haploids from the anther callus. The survival of anthers of three clones such as TRI 2043, TRI 2023 and TRI 2025 was high (78-98\%) among the clones tested. TRI 2043 was the most effective in producing the calli from anthers grown in light. In dark, significant callus growth was observed in anthers of four clones (TRI 2025, TRI 2024, TRI 2043 and TRI 777). Though the callus formation from anthers was successful, plantlets could not be regenerated yet. Therefore, continued effort and screening of calli with various combinations of hormones is required to produce the haploids. 


\section{References}

1. Anandappa T.I., Nanayakkara R. \& Solomon H.R. (1988). Seed setting abilities of some Sri Lankan tea clones and their implications for tea breeding. In: Proceedings of the regional tea (scientific) conference. pp. $73-87$.

2. Katsuo K. (1969). Anther culture in tea plant (a preliminary report). Study of Tea 4: 31 .

3. Okano N. \& Fuchinone Y. (1970). Production of haploid plants by anther culture of tea in vitro. Japan. Journal of Breeding 20:63-64.

4. Doi Y. (1981). Frequency of root differentiation in anther culture of tea. Study of Tea $60: 1-3$.

5. Murashige T. \& Skoog F. (1962). A revised medium for rapid growth and bioassays with tobacco tissue culture. Physiologia Plantarum 15: 473 - 497.

6. Pan Jing Li., Gao Gong-hong \& Dan Hai (1983). Initial types of wheat pollen cells and their development in anther culture. In: Cell and tissue culture techniques for cereal crop improvement. pp 117-129. Proceedings of a workshop co-sponsored by the Institute of Genetics, Academic Sinica and The International Rice Research Institute. Science press, Beijing.

7. Dolezel J. (1991). Review paper: Flow Cytometric Analysis of Nuclear DNA content in higher plants. Photochemistry Analysis 2: 143-154

8. PARTEC (1996). User manual for a ploidy analyser. Partec Gmbh, Munster, Germany.

9. Gomez K.A \& Gomez A.A (1984). Statistical procedure for agricultural research. John Wiley, New York.

10. Chen Z. (1984). Rubber (Hevea). In: Hand book of plant cell culture, Vol 2 Crop species (Eds. W.R.Sharp., D.A.Evans., P.V. Ammirato \& Y.Yamada). pp. 546-571. Macmillan, New York.

11. Pedroso M.C. \& Pais M.S. (1994). Induction of microspore embryogenesis in Camellia japonica cv. Elegans. Plant Cell Tissue and Organ Culture 37: $129-136$.

12. Razdam M.K. (1993). Haploid production. In: Introduction to plant tissue culture. pp. 105-123. Intercept Ltd, Andover, Hampshire, U.K. 
13. Radojevic L. (1991). Horse Chestnut (Aesculus spp). In: Biotechnology in agriculture and forestry Vol 16. (Ed. Y.P.S. Bajaj). pp. 111-141. Springer-Verlag, Berlin and Heidelberg.

14. Ulrich I. \& Ulrich W. (1991). High resolution flow cytometry of nuclear DNA in higher plants. Protoplasma 165: 212-215.

15. Uijtewaal B.A.(1987). Ploidy variability in green house cultured and in vitro propagated potato (Solanum tuberosum) monohaploids $(2 \mathrm{n}=\mathrm{x}=12)$ as determined by flow cytometry. Plant Cell Report. 6: 252-255.

16. Sarwar M. (1985). Callus formation from explanted organs of tea (Camellia sinensis). Sri Lanka Journal of Tea Science 54: 18 - 22.

17. Skoog F. \& Miller C.O. (1957). Chemical regulation of growth and organ formation in plant tissues cultured in vitro. Symposia of the Society for Experimental Biology 11: 118 - 131.

18. Niizeki H. \& Oono K. (1968). Induction of haploid rice plant from anther culture. Proceedings of Japanese Academy 44: 554-557.

19. Guha-Mukherjee S. (1973). Genotypic differences in the in vitro formation of embryoids from rice pollen. Journal of Experimental Botany 24: 139-144.

20. Martin J.A. \& Gella R. (1991). Sourcherry (Prunus cerasus L.). In: Biotechnology in agriculture and forestry, Vol 16:Trees III. (Ed. Y.P.S.Bajaj). pp. 24-41. Springer-Verlag, Berlin and Heidelberg. 